\title{
An evaluation of SOA modelling in the Madrid metropolitan area
}

\author{
M. G. Vivanco, I. Palomino, J. Plaza, B. Artíñano, M. Pujadas \\ \& B. Bessagnet \\ CIEMAT, Madrid, Spain
}

\begin{abstract}
The improvement of air quality represents an important challenge for our society. In urban areas, air quality standards are being exceeded. Like other tropospheric pollutants, aerosols are presently under regulation in the European Union. Control of aerosol concentration is an important objective, because high levels can affect human health. As an indirect effect, aerosols can alter earth's radiative budget by scattering or absorbing radiation, producing a change of ozone production. Because of both direct and indirect aerosol effects, it is important to know aerosol levels in the troposphere.

Models can be used as a tool for air quality management. Secondary organic aerosol (SOA) is presently one of the most important topics on air quality modelling. Many aspects of SOA modelling are still a challenge for the scientific community. Unfortunately, the quality of model results cannot be evaluated because SOA measurements are not available at air quality stations. The reason for that is that it is not possible to distinguish experimentally a primary organic aerosol from a secondary one.

In this paper, an air quality model was used to simulate hourly SOA concentrations during a 2003 summer period in the Madrid metropolitan area. A simple reaction scheme for SOA was used. Modelled SOA was compared against SOA estimations obtained from thermal $\mathrm{OC}$ and $\mathrm{EC}$ hourly measurements at an urban background site, using the $\mathrm{OC} / \mathrm{EC}$ minimum ratio approach. Although a reasonable agreement is observed, higher-resolution simulations with higher-resolution emissions should be carried out in order to improve model predictions. Also, a more complex scheme of SOA formation should be tested to determine the origin of the discrepancies.
\end{abstract}

Keywords: secondary organic aerosols, air quality modelling, organic carbon, elemental carbon. 


\section{Introduction}

In the urban atmosphere fine particulate matter includes primary and secondary organic and inorganic compounds. Secondary organic aerosol (SOA) can have a relevant presence, especially during smog episodes. Its formation involves the presence of oxidation products with a low pressure vapour in order to be able to partition in aerosol phase. Some research has been done over the last decade to describe the SOA formation from many reactive organic compounds [1-5].

It is difficult to represent atmospheric SOA formation in air quality models due to the complexity of the processes involved and the uncertainties affecting SOA precursor emissions. Some models use the lumped SOA yield based on [6]. According to the authors, oxidation reactions for each class of VOC are assumed to lead to a fixed fraction of SOA product.

The CHIMERE model has been extensively applied over the past year [7-11]. In Spain, evaluation of the model performance for $\mathrm{O} 3$ and NO 2 has been shown in [12]. This study has indicated that $\mathrm{O} 3$ predictions are in a reasonably agreement to observations registered at rural sites. The capability to reproduce PM10 and PM2.5 has also been evaluated in [13].

As SOA cannot be directly recorded in the real atmosphere, techniques to estimate SOA formation from measurements of organic and elemental carbon are commonly used. Elemental carbon is defined as the material that will not thermally desorb from a filter sample and is generally attributed to graphitic, soot-like structures. It is assumed to be exclusively due to primary emission. Organic is defined as material that will thermally desorb from a filter sample and may be associated with either primary or secondary aerosol [14-16]. To estimate SOA values, a methodology based on the ratio of organic to elemental carbon in the primary aerosol is used. As this quantity is not accurately known, SOA estimates using this approach may be subject to inaccuracies. In spite of this limitation organic and elemental carbon measurements are frequently the only data about the carbonaceous component of atmospheric aerosol. That is the reason why this approach is commonly used.

\section{OC-EC semicontinuous measurements}

Measurements of carbonaceous aerosol concentration (EC/OC) were carried out using a thermal analyzer (Rupprecht and Patashnick model 5400) at a sub-urban site in Madrid (CIEMAT station).

The analyzer collects PM2.5 carbonaceous aerosol using an impactor with a cut-off diameter of $0.14 \mathrm{~mm}$ prior to its sequential oxidation with particle-free ambient air. The $\mathrm{CO} 2$ produced is analyzed and its concentration is related to carbon mass in both aerosol fractions (OC and EC). One-hour sampling and analysis cycle was set-up, being the combustion temperatures to obtain OC and EC concentrations $340^{\circ} \mathrm{C}$ and $750^{\circ} \mathrm{C}$ respectively. The EC concentration was corrected accounting for material loss due to the cut-off size of the impactor, from simultaneous $24 \mathrm{~h}$ filter samples and EC and OC measurements using a thermal carbon analyzer (LECO) at the same split temperature. 


\section{Estimation of SOA from measurements}

Based on the high temporal resolution of EC-OC measurements, a method to calculate primary $\mathrm{OC} / \mathrm{EC}$ ratio from traffic has been applied in polluted days (EC hourly maximum $>4 \mu \mathrm{gm}^{-3}$ ). Background values have been considered to subtract from EC and OC values at the time of maximum EC slope during morning or evening rush hours. Usually the morning maximum slope in EC takes place before sunrise, thus this calculation avoids computing secondary OC [17]:

$$
\left(\frac{O C}{E C}\right)_{\text {primary }}=\frac{O C_{\Delta E C_{\max }}-O C_{\text {background }}}{E C_{\Delta E C_{\max }}-E C_{\text {background }}}
$$

The method to estimate SOA from OC and EC measurements in this suburban site was the subtraction of traffic primary $\mathrm{OC}$ from measured $\mathrm{OC}$, i.e. the minimum ratio approach [18]):

$$
\left.\mathrm{SOA}=\mathrm{OC}_{\text {measured }}-(\mathrm{OC} / \mathrm{EC})_{\text {primary }} \cdot \mathrm{EC}\right)
$$

The calculated OC/EC traffic primary ratio was $0.47 \pm 0.26$ (average \pm std, $\mathrm{n}=59,42$ morning and 17 evening estimations from a 18 -month period). Primary $\mathrm{OC}$ due to other minor sources is not considered in this method of SOA estimation, so the obtained value can be seen as an upper limit.

\section{CHIMERE model SOA scheme}

The V2006-par version of the CHIMERE model calculates the concentration of 44 gaseous species and both inorganic and organic aerosols of primary and secondary origin, including primary particulate matter, mineral dust, sulphate, nitrate, ammonium, secondary organic species and water. In this version a very simplified scheme for SOA formation is implemented in the chemical module MELCHIOR. Precursor volatile organic compounds able to form secondary aerosol species are high chain alkanes, aromatics and monoterpenes. Anthropogenic aerosol yields (ASOA) come from [1, 2, 6, 19]. ASOA in this scheme is originated by the reaction between alkanes with four or more carbon atoms and ortho-xylene with $\mathrm{OH}$ radical. For biogenic secondary organic aerosols (BSOA), aerosol yields for terpene oxidation are taken from [20]. Biogenic SOA are formed from alpha pinene reacting with $\mathrm{OH}$ radical and with ozone. The reactions included in MELCHIOR2 mechanism are presented in Table 1. ASOA and BSOA are partitioned between gas and aerosol phases. Mass transfer is not only driven by the gas phase diffusion but also by the thermodynamic equilibrium through a temperature dependent partition coefficient [21]. 
Table 1: $\quad$ Reactions in CHIMERE V2006par version for SOA formation.

\begin{tabular}{lll}
\hline \hline $\mathrm{N}_{-} \mathrm{C}_{4} \mathrm{H}_{10}+\mathrm{OH}$ & $\rightarrow$ & $0.9 \mathrm{CH}_{3} \mathrm{COCH}_{2} \mathrm{CH}_{3}+0.1 \mathrm{CH}_{3} \mathrm{CHO}+0.1$ \\
& $\mathrm{k} 1(\mathrm{~T})$ & $\mathrm{CH} 3 \mathrm{COO}+0.9 \mathrm{oRO}_{2}+0.04 \mathrm{SOA}$ \\
o-xylene $+\mathrm{OH}$ & $\rightarrow$ & $\mathrm{MEMALD}+\mathrm{MGLYOX}+\mathrm{oRO} 2+0.2 \mathrm{SOA}$ \\
& $\mathrm{k} 2$ & \\
$\alpha$-pineno $+\mathrm{OH}$ & $\rightarrow$ & $0.8 \mathrm{CH}_{3} \mathrm{CHO}+0.8 \mathrm{CH}_{3} \mathrm{COCH}_{2} \mathrm{CH}_{3}+$ obio +0.07 \\
& $\mathrm{k} 3(\mathrm{~T})$ & $\mathrm{SOA}$ \\
\hline$\alpha$-pineno $+\mathrm{O} 3$ & $\rightarrow$ & $1.27 \mathrm{CH} 3 \mathrm{CHO}+0.53 \mathrm{CH} 3 \mathrm{COCH} 2 \mathrm{CH} 3+0.14 \mathrm{CO}$ \\
& $\mathrm{k} 4(\mathrm{~T})$ & $\begin{array}{l}0.62 \mathrm{ORO} 2+0.42 \mathrm{HCHO}+0.85 \mathrm{OH}+0.1 \mathrm{HO} 2+ \\
0.23 \mathrm{SOA}\end{array}$ \\
& & \\
\hline
\end{tabular}

MEMALD: unsaturated dicarbonyls, reacting like 4-oxo-2-pentenal; MGLYOX: methyl glyoxal; obio: operator representing peroxy radicals produced by $\mathrm{C} 5 \mathrm{H} 8$ and $\mathrm{APINEN}+\mathrm{OH}$ reaction; oRO2: operator representing peroxy radicals from $\mathrm{OH}$ attack to $\mathrm{C} 2 \mathrm{H} 5, \mathrm{NCHH} 10, \mathrm{C} 2 \mathrm{H} 4$, C3H6, OXYL, CH3COE, MEMALD, and MVK (methyl vinyl ketone).

$\mathrm{k} 1(\mathrm{~T})=1.3610^{-12} \mathrm{e}^{0.0021 \mathrm{~T}} \quad \mathrm{k} 2=1.3710^{-11} \quad \mathrm{k} 3(\mathrm{~T})=1.2110^{-11} \mathrm{e}^{444 / \mathrm{T}}$
$\mathrm{k} 4(\mathrm{~T})=10^{-15} \mathrm{e}^{-736 / \mathrm{T}}$

\section{Model simulations}

Simulations of photochemical compounds were carried out using the regional V200603par-rc1 version of the CHIMERE model. Modelling scheme to obtain SOA concentrations was the same as that described in [13]. First, the CHIMERE model was applied for a coarse domain of $0.5^{\circ}$ of resolution at European scale, covering an area ranging from $10.5 \mathrm{~W}$ to $22.5 \mathrm{E}$ and from $35 \mathrm{~N}$ to $57.5 \mathrm{~N}$ with 14 vertical sigma-pressure levels extending up to $500 \mathrm{hPa}$. A second domain was focused over the Iberian Peninsula (from $10.3 \mathrm{~W}$ to $5.5 \mathrm{E}$ and from $35.5 \mathrm{~N}$ to $44.5 \mathrm{~N}$ ), with a 0.2 degree resolution. A one-way nesting procedure was used; coarse-grid simulations forced the fine-grid ones at the boundaries without feedback.

The emissions for all the simulations were derived from the annual totals of the EMEP database for 2003 [22]. Original EMEP emissions were disaggregated taking into account the land use information, in order to get higher resolution emission data. The spatial emission distribution from the EMEP grid to the CHIMERE grid is performed using an intermediate fine grid at $1 \mathrm{~km}$ resolution. This high-resolution land use inventory comes from the Global Land Cover Facility (GLCF) data set (http://change.gsfc.nasa.gov/create.html). For each SNAP activity sector, the total NMVOC emission is split into emissions of 227 real individual NMVOC according to the AEAT speciation [23], and real species emissions are aggregated into model species emissions. Biogenic emissions are computed according to the methodology described in [24], for alpha-pinene, NO and isoprene. 
Boundary conditions for the coarse domain were provided from monthly 2003 climatology from LMDz-INCA model [25] for gases concentrations and from monthly 2004 GOCART model [26] for particulate species.

The MM5 model [27] was used to obtain meteorological input fields. The simulations were carried out also for two domains, with respective resolutions of $36 \mathrm{Km}$ and $19 \mathrm{Km}$. The simulations were forced by the National Centres for Environmental Prediction model (GFS) analyses.

\section{Results}

In order to illustrate the capability of the CHIMERE model to simulate SOA levels, time series of both predicted and based on observations SOA concentrations are presented in Figure 1.

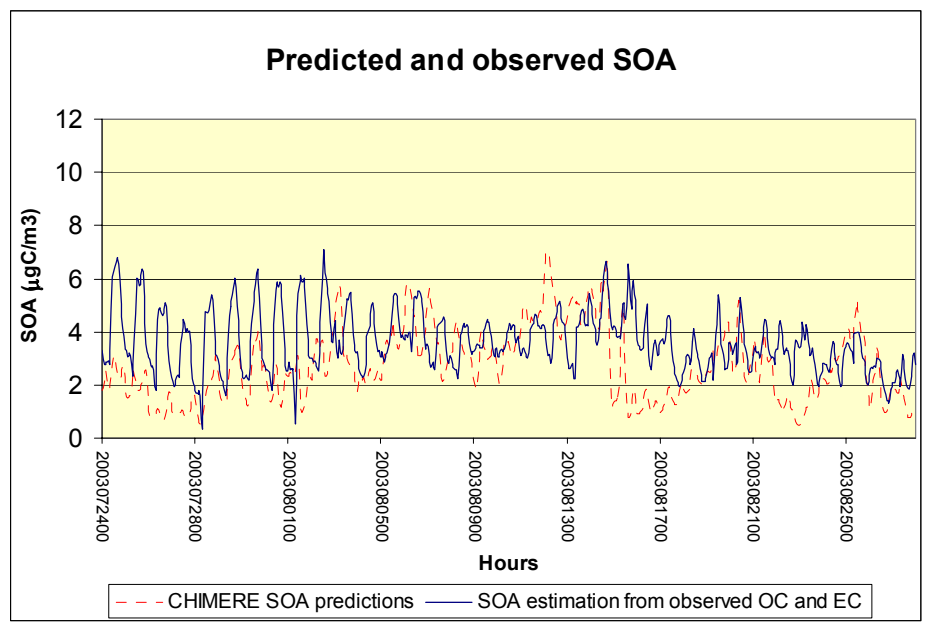

Figure 1: Time series of predicted and based on observations estimated SOA.

In general a good correlation between both SOA time series is found, although there are some discrepancies for some periods, such as August 3-5, August 11-13 and August 21-23. For the period 14-17, in spite of a good correlation a considerable underestimation is observed.

Figure 2 presents time series for other pollutants, such as O3, NO2, NOx and PM10 at "Barrio del Pilar" station, an urban traffic site close to CIEMAT station. Observed and MM5 predicted temperature, wind speed and wind direction are also included in this figure. Ozone temporal variability is quite well reproduced by the model. NO2 and NOx present a good correlation, although high observed concentrations are not reproduced by the CHIMERE model. As this monitoring site is located close to mobile sources, high levels are recorded. Figure 2 also indicates an important underestimation of PM10 model predictions. High resolution simulations and high-resolution emissions need to be used to reproduce those local effects. 


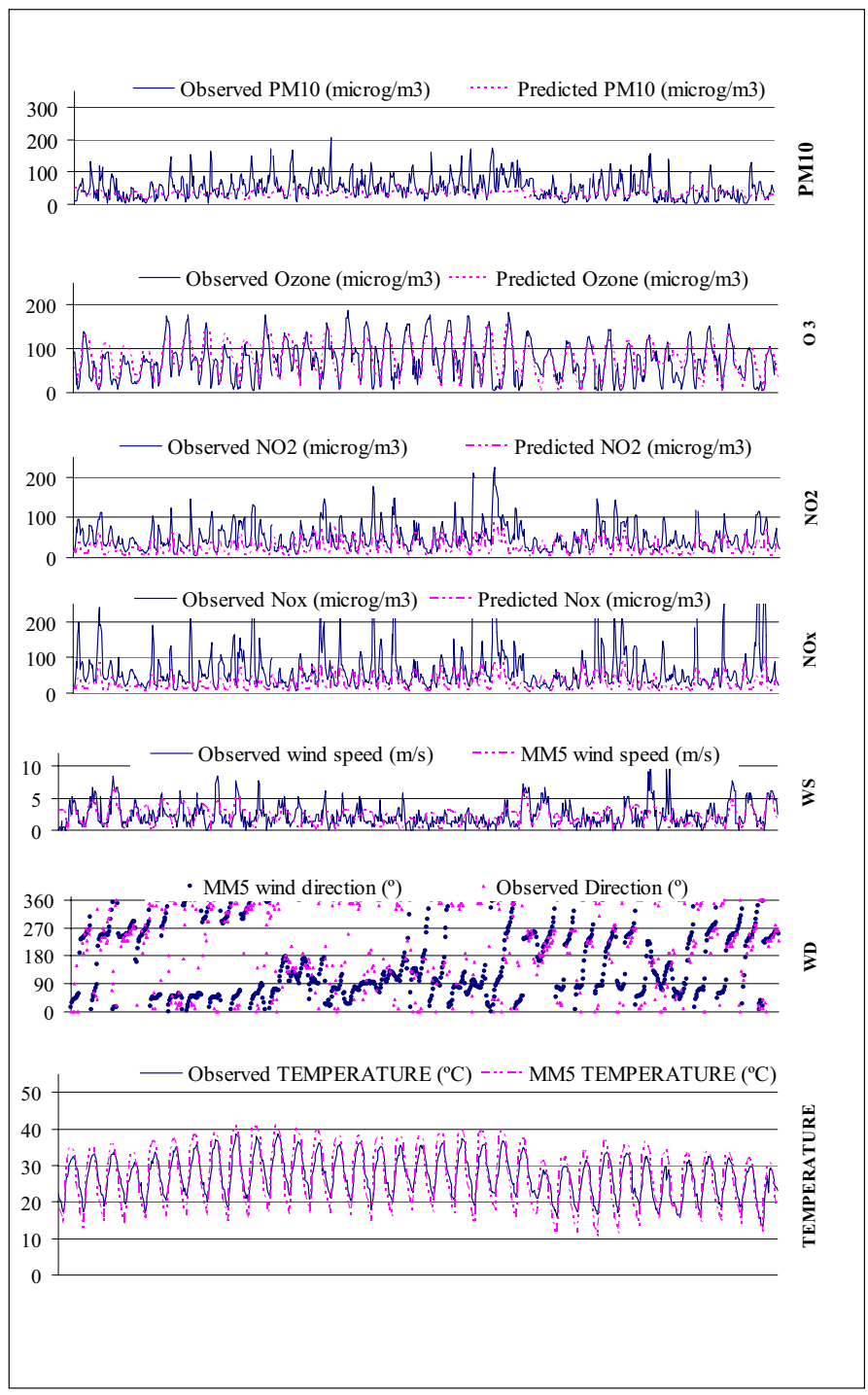

Figure 2: Time series presenting predictions and observations of some pollutant concentrations and some meteorology variables at a suburban site.

\section{Conclusions}

The present paper shows the results of a graphical evaluation of the SOA levels predicted by the CHIMERE photochemical model. Although, in general, model predictions present values similar to SOA levels estimated from EC and $\mathrm{OC}$ 
observations, some underestimation is found for some periods. These results have been obtained for $0.2^{\circ} \times 0.2^{\circ}$ horizontal resolution. High- resolution simulations should be carried out in order to determine if the discrepancies are due to the coarse resolution. Also, high-resolution emissions should be used to better represent local effects. Presently, a $4 \times 4 \mathrm{~km}^{2}$ emission inventory, developed at he Barcelona Supercomputing Centre (BSC) is being applied.

A new version of the CHIMERE model is now available. It incorporates more reactions involving SOA formation. This version is presently being evaluated in order to determine if an improvement of SOA model predictions is obtained.

\section{Acknowledgement}

The authors kindly acknowledge the support by the Spanish Environment Ministry.

\section{References}

[1] Odum, J. R.; T. Hoffmann, F. Bowman, D. Collins, R.C. Flagan, J.H. Seinfeld (1996). Gas/particle partitioningandsecondary organic aerosol yields. Environ. Sci. Technol., 30, 2580-2585.

[2] Odum J.R., Jungkamp T.W.P., R.J. Griffin, R.C. Flagan, J.H.Seinfeld (1997). The atmospheric aerosol formation potential of whole gasoline vapor. Science 274, 96-99.

[3] Zhang, S. H., M. Shaw, J.H. Seinfeld, and R.C. Flagan (1992), Photochemical aerosol formation from a- and b-Pinene, Geophy. Res., 97, 20717-20730 .

[4] Griffin R.J., D. R. Cocker, J.H. Seinfeld, D. Dabdub, (1999). Estimate of global atmospheric organic aerosol from oxidation of biogenic hydrocarbon. Geophysical Research Letters, Vol. 26, No.17, 2721-2724.

[5] VanReken, T. M., J. P. Greenberg, P. C. Harley, A. B. Guenther, and J. N. Smith (2006). Direct measurement of particle formation and growth from the oxidation of biogenic emissions

[6] Grosjean, D. and J.H. Seinfeld (1989). Parametrization of the formation potential of secondary organic aerosol. Atmos. Environ., 23. 1733-1747.

[7] Vautard. R., B. Bessagnet, M. Chin and L. Menut (2005). On the contribution of natural Aeolian sources to particulate matter concentrations in Europe: Testing hypotheses with a modelling approach, Atmospheric Environment., 39, 3291-3303.

[8] Bessagnet, B., A. Hodzic, R. Vautard, M. Beekmann, L. Rouil, R. Rosset (2004). Aerosol modelling with CHIMERE -first evaluation at continental scal . Atmospheric Environment 38, 2803-2817.

[9] Derognat, C., M. Beekmann, Bäumle, D. Martin (2003). Effect of biogenic volatile organic compound emissions on tropospheric chemistry during the atmospheric pollution over the Paris area (ESQUIF) campaign in the Ile-deFrance region. Journal of Geophysics Research 108 (D14), 4409-4423. 
[10] Hodzic, A., R. Vautard, B. Bessagnet, M. Lattuati, and F. Moreto (2005). On the quality of long-term urban particulate matter simulation with the CHIMERE model. Atmospheric Environment, 39, 5851-5864.

[11] Schmidt, H., C. Derognat, R. Vautard, M. Beekmann (2001). A comparison of simulated and observed ozone mixing ratios for the summer of 1998 in western Europe. Atmospheric Environment 35, 6277-6297.

[12] Vivanco, M.G., I. Palomino, R. Vautard, B. Bessagnet, F. Martín, L. Menut, S. Jiménez (2008). Multi-year assessment of photochemical air quality simulation over SPAIN, Environmental Modelling \& Software. In press.

[13] Vivanco, M.G., I. Palomino, F. Martín, M. Palacios (2007). Modelling Atmospheric Particles in the Iberian Peninsula and Balearic Islands. 11th International Conference on Hermonisation within Atmospheric Dispersion Modelling for Regulatory Purposes, Cambridge, UK. Volume 2, 48-52.

[14] Turpin, B. J., J.J. Huntzicker., S.M. Larson and G.M. Cass (1991) Los Angeles summer midday particular carbon: Primary and secondary aerosol, Environ. Sci. Technol., 25, 1788-1793.

[15] Turpin, B. J. and J.J. Huntzicker (1991) Secondary formation of organic aerosol in the Los Angeles basin: A descriptive analysis of organic and elemental carbon concentrations, Atmos. Environ., 25A, 207-213.

[16] McMurray, P. H., and X.Q. Zhang (1989) Size distributions of ambient organic and elemental carbon, Aerosol Science and Technology, 10, 430437.

[17] Artíñano, B., J. Plaza, F.J. Gómez-Moreno, M. Pujadas, L. Núñez (2007), Analysis of $P M_{2.5}$ OC-EC semicontinuous thermal measurements in Madrid, $2^{\text {nd }}$ ACCENT Symposium

[18] Castro, L.M., C.A. Pio, R.M. Harrison, D.J.T. Smith (1999), Carbonaceous aerosol in urban and rural European atmospheres: estimation of secondary organic carbon concentrations, Atmos. Environ. 33, 2771-2781

[19] Schell, B., Ackermann, I. J., Hass, H., Binkowski, F. S., and Ebel, A. (2001). Modeling the formation of secondary organic aerosol within a comprehensive air quality modeling system. J. Geophys. Res., 106:2827528293.

[20] Pankow, J. F. (1994). An absorption model of gas/aerosol partition involved in the formation of secondary organic aerosol. Atmos. Environ., 28:189-193.

[21] Pankow, J.F., J.H. Seinfeld, W.E. Asher, and G.B. Erdakos (2001). Modeling the formation of secondary organic aerosol. 1. Application of theoretical principles to measurements obtained in the _-pinene, _-pinene, sabinene, 3-carene and cyclohexene/ozone systems. Environmental Sci. and Tech., 35:1164-1172.

[22] Vestreng, V., K. Breivik, M. Adams, A. Wagener, J. Goodwin, O. Rozovskkaya, J. M. Pacyna (2005). Inventory Review 2005, Emission Data reported to LRTAP Convention and NEC Directive, Initial review of HMs and POPs, Technical report MSC-W 1/2005, ISSN 0804-2446. 
[23] Passant, N. R., 2002. Speciation of UK emissions of non-methane volatile organic compounds. AEAT/ENV/R/0545 Issue 1.

[24] Simpson, D., A. Guenther, C.N. Hewitt, and R. Steinbrecher (1995). Biogenic emissions in Europe 1. Estimates and uncertainties, Journal of Geophysical Research 100(D11), 22875-22890.

[25] Hauglustaine, D. A., F. Hourdin, L. Jourdain, M.-A Filiberti,., S. Walters., J.-F. Lamarque,., and E. A. Holland, (2004). Interactive chemistry in the Laboratoire de Météorologie Dynamique general circulation model: Description and background tropospheric chemistry evaluation, J. Geophys. Res., 109, doi:10.1029/2003JD003957.

[26] Chin, M., P. Ginoux, S. Kinne, B. N. Holben, B. N. Duncan, R. V. Martin, J. A. Logan, A. Higurashi, and T. Nakajima (2002). Tropospheric aerosol optical thickness fromt he GOCART model and comparisons with satellite and sunphotometer measurements, J. Atmos. Sci. 59, 461-483.

[27] Grell G.A., J. Dudhia, D.R. Stauffer (1995). A Description of the FifthGeneration Penn State/NCAR Mesoscale Model (MM5).NCAR/TN-398 + STR. NCAR TECHNICAL NOTE. 